\title{
Positive and Negative Sequence Voltage Compensation Using Statcom at Wind Farm
}

\author{
Mohini Moitra $^{1}$ \\ ${ }^{1}$ Department of Electrical and Electronics Engineering, Chouksey Engineering College, Bilaspur, India
}

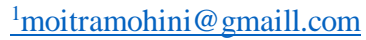

\begin{abstract}
The study of shunt connected FACTS devices is a connected field with the problem of positive and negative voltage compensation and better mitigation of instability problems in today's world. In this project, the shunt operation of FACTS controller is studied, the STATCOM, and how it helps in the better utilization of a network operating under normal conditions. First literature review of many papers related to FACTS and STATCOM is carried out, along with positive and negative voltage compensation. The study of STATCOM and its principles of operation and control, including phase angle control and PWM techniques, are carried out. The study of shunt connected devices is a shunt connected field positive and negative sequence voltage compensation and better mitigation of transmission related world. Statcom is a FACTS device whose capacitive or inductive current can be controlled independent of system ac voltage. Whenever an asymmetrical fault occurs in a system, power loss and voltage instability can occur in that system. So to increase the life time of generator drives and to reduce that voltage instability, Statcom can be used. Statcom can compensate positive sequence voltage for improving voltage stability and for reducing torque ripples negative sequence voltage has to be compensated. Statcom can perform coordinated action regarding positive and negative voltage compensation. In this thesis, review of positive and negative voltage compensation and results for positive sequence voltage compensation and negative voltage compensation using MATLAB simulation is shown.
\end{abstract}

Keywords - StatCom, wind farm, PWM technique, positive sequence voltage and negative sequence voltage.

\section{Introduction}

In order to achieve renewable energy and $\mathrm{CO}_{2}$ emission reduction targets, significant amounts of wind energy need to be integrated into Europe's electricity system. Start of the art wind power technology with advanced control features is designed to enhance grid performance by providing ancillary services. Using these power plant characteristics to their full potential with a minimum of curtailment of wind power is essential for efficiently integrating high levels of wind power. The wind farms which are recently installed are of variable speed type. Variable speed type generators are of two types, doubly fed induction generator (DFIG) or permanent-magnet synchronous generator. But out of these, still $15 \%$ of wind farms works on fixed speed induction generator (FSIG) in Europe in 2010 [3]. Whenever there is a voltage dip in a system, the induction generator may consume a large amount of reactive power because their speed deviates from synchronous speed which can results into progression of faults and voltage collapse [4]. Whenever unsymmetrical faults occurs in a wind farm, positive and negative sequence voltages are generated. Positive sequence voltage causes voltage instability and negative sequence voltage causes heavy generator torque oscillations which leads to mechanical vibration. StatCom is a FACTS device that can be used for eradicating positive and negative sequence voltages produced in a wind farms. StatCom is a type of static synchronous generator. It is a device whose capacitive or inductive output current can be controlled irrespective of its ac voltage [1]. For different output power distributions, StatCom may be applied by different current injection methods based on symmetrical components [16]. The main aim of using StatCom in a transmission network is the fast regulation of voltage at a load or an intermediate bus. Available transfer capacity (ATC) and power transfer capacity can also be increased with the help of application of StatCom [2]. For stabilization of fixed speed generator system, different efficient methods can be used. Some of them are StatCom, pitch control system, braking resistor (BR) and superconducting magnetic energy storage (SMES).Out of these methods, StatCom has been identified to provide the best dynamic stability enhancement capability [5]. After comparison with various converter topologies, the chain converter is found to be most attractive choice for implementation of static compensator (StatCom) [6]. By comparing various parameters of StatCom and SVC, it is found out that StatCom has low losses, better performances, improved wind farm stability and better reactive power support to network [7-10]. Double fed induction generator has many advantages over fixed speed induction generator [11]. The degree up to which the StatCom can compensate the voltage depends largely on the choice of current rating of StatCom and impedance of power system. If power system is weak and high current rating is applied to StatCom then capability of voltage compensation of StatCom is also increased [12]. While designing and dimensioning machines 
and converters, negative sequence voltages and currents resulting from system faults have to be considered as they cause oscillating torques and damping which may structural load to gear box as well as drive train [13]. In DFIG if there is condition of unbalanced grid voltage, then the major problem are the dc voltages ripples in the back to back VSCs and torque pulsations [15].

\section{Problems in wind farm integration with Grid}

FACTS technology plays a vital role in enhancing the power system performance and improving the stability and life span of the system. The installations must meet requirements of the grid connection codes such as fault ride through capability [8], voltage control and frequency range and control. Induction generators are used for fixed speed operation. The main drawback is that the grid has to supply power to load, lines and also the generator. It is therefore essential to meet the variable VAR requirements within the wind farm locality. After the occurrence of fault conditions, the IG draws more reactive power from the grid and the voltage stability will be impossible, due to which there will be voltage collapse at the terminals [4]. During a grid fault, the wind farms can be disconnected from the grid and again connected when normal conditions have regained. The integration of wind farm with electrical system has been started to influence the overall power system. Wind being the climatically uncontrolled resource as wind flow varies according to climate, it is very necessary to reduce the problems occurring in the integration of wind farms with grid.

\section{Possible remedy is STATCOM}

STATCOM is a power electronics revolution which offers advantages of high speed, reliability of switching and enhanced the value of electric energy. The ability of STATCOM to increase available transfer capability, smoothing reactive power, improve reliability and to enhance operation and control has made is a correct choice for solving installation problems. STATCOM prevents large deviations of bus voltage magnitude induces by reactive power drawn from grid during an external fault [1]. It is faster, smaller. It has better performance at low voltage conditions. To reduce voltage instability and torque ripples on integrating wind energy into grid, a STATCOM control mechanism is preferable. Harmonic part of the load current and voltage can also be eliminated or reduced by STATCOM. STATCOM can improve the voltage profile at the PCC during faults by regulating the reactive power of the grid. IT maintains the level of voltage sag so that the turbine can be continuously connected to the grid. Adequate reactive power compensation, optimum design of wind turbines can play a vital role in minimizing the voltage instability and increasing life span of generator drives [3].

\section{Principle of operation of STATCOM}

A StatCom is shown in fig.1 as below. A static synchronous compensator (StatCom) is also called static synchronous condenser. It is member of FACTS family of devices. It is type of regulating device which is used on alternating current electricity transmission networks. StatCom can operate as either a source or sink of reactive AC power to an electricity network and the basis of this device is power electronics voltage source converter [3]. It is modular and electable. StatCom is installed in a wind farm in order to improve power factor and voltage regulation therefore StatCom can be used for voltage stability. The active power capability of StatCom is very less. Therefore if an appropriate energy storage device is inserted across DC capacitor then its active power capability can be improved. The response time of StatCom is less than SVC. Better reactive power support at low AC voltages can be provided by StatCom. To improve power flow and transient stability in power grids StatCom is used which works on power electronics devices. StatCom generates reactive power if system voltage is low and it absorbs reactive power if system voltage is high [2].

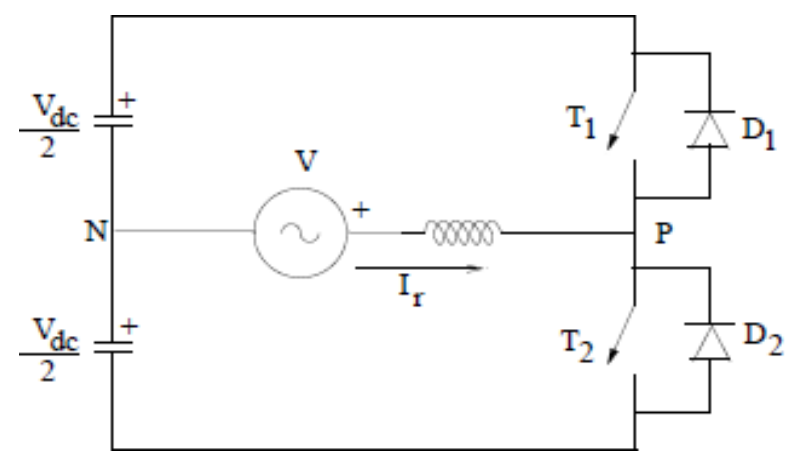

Fig. 1 A single phase StatCom

The principle of operation of StatCom is shown in below fig. 2 . In this figure power transfer between active and reactive power between source V1 and V2 is shown where V1 is system voltage to be controlled and V2 is voltage generated by VSC.

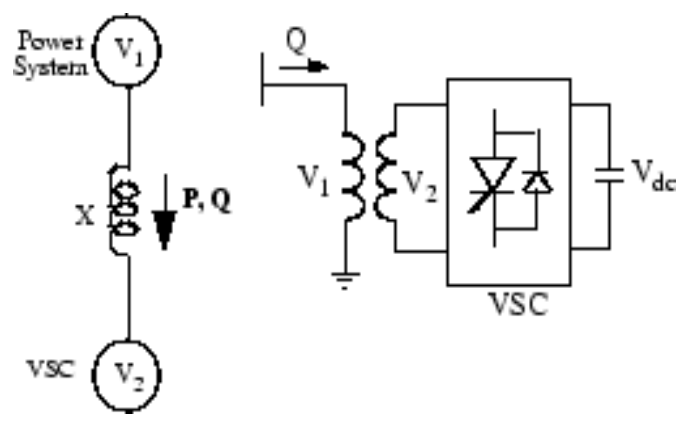

Fig. 2 Principle of operation of StatCom

$\mathrm{P}=(\mathrm{V} 1 \mathrm{~V} 2) \sin \delta / \mathrm{X}$ 
$\mathrm{Q}=\mathrm{V}_{1}\left(\mathrm{~V}_{1}-\mathrm{V}_{2} \cos \delta\right) / \mathrm{X}$

$\mathrm{V} 1=$ Line to line voltage of source

$\mathrm{V} 2=$ Line to line voltage of source 2.

$\mathrm{X}=$ Interconnecting transformer and filters reactance. $\delta=$ Phase angle of V1 with respect to V2.

At $\delta=0$, V2 is in phase with V1and therefore only reactive power flows. This is the condition during steady state.

If $\mathrm{V} 2$ is less than $\mathrm{V} 1$ then StatCom will absorb reactive power. If V2 is greater than V1, the StatCom will generate reactive power.

Reactive power is $\mathrm{Q}=(\mathrm{V} 1(\mathrm{~V} 1-\mathrm{V} 2)) / \mathrm{X}$

A capacitor connected on the DC side of the VSC acts as a DC voltage source. In steady state the voltage V2 has to be phase shifted slightly behind V1 in order to compensate for transformer and VSC losses and to keep the capacitor charged.

\section{PWM technique used for STATCOM}

Sinusoidal PWM technique:-

Fundamental line to line converter voltage is controlled by sinusoidal PWM technique. The three phase converter voltage can be obtained by comparing sinusoidal voltage waveform with triangular voltage waveform. The modulating frequency is equal to the supply frequency in StatCom. The Amplitude modulation ratio is given by,

$\mathrm{m}_{\mathrm{a}}=\mathrm{V}_{\text {control }} / \mathrm{V}_{\text {tri }}$

Where $V_{\text {control }}$ is the peak amplitude of the control voltage waveform and $\mathrm{V}$ is the peak amplitude of triangular voltage waveform. The range of SPWM is $0 \leq \mathrm{m}_{\mathrm{a}} \leq 1$. The Dc link voltage value is regulated by StatCom to a fixed one in all modes of operation in constant DC link scheme. The peak StatCom fundamental voltage from full inductive mode of operation to full capacitive mode of operation at minimum and maximum voltage value determines this fixed value. So for $0 \leq \mathrm{m}_{\mathrm{a}} \leq 1$, the fundamental voltage is varied by varying $\mathrm{m}_{\mathrm{a}}$ in the linear range.

\section{System configuration and control model of STATCOM}

The block diagram of the system and control model is shown in below fig. 3. The control scheme used for StatCom control structure is voltage oriented vector control method. The wind farm structure consists of StatCom, transformers, transmission lines and grid lines. The StatCom is coupled with transformers in order to compensate positive and negative sequence voltages. The sinusoidal pulse width modulation is applied to StatCom control model. The sinusoidal pulse width modulation consists of adder circuit and gate devices [15]. The gate devices are triggered by triggering pulses and adder circuit provide signals to in SPWM model. In this control structure with inner proportional integral (PI) current controllers, grid voltage orientation is in a rotating d-q frame [4].

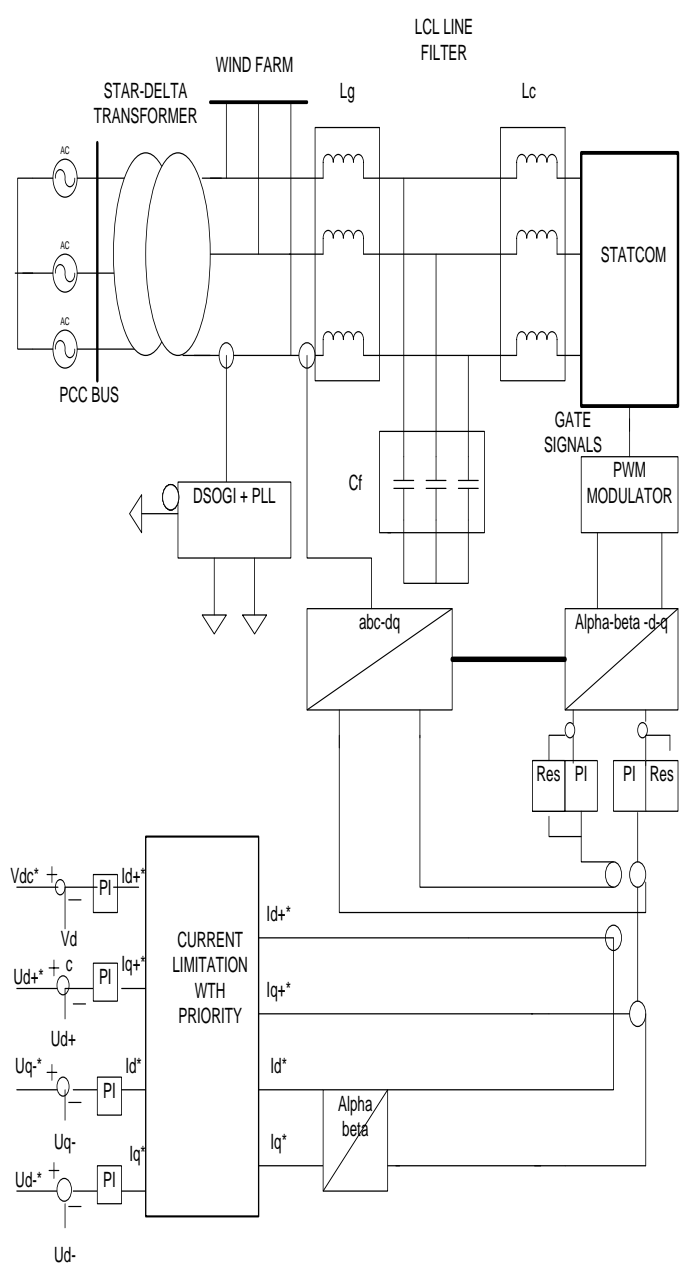

Fig. 3 Voltage and current at sending end for single phase to ground fault without STATCOM 


\section{CACULATIONS OF SEQUENCE VOLTAGES}

\section{POSITIVE SEQUENCE VOLTAGE}

Positive sequence voltage is shown below in fig.3. Positive sequence voltage is calculated as follows:-

$E_{r 1}=\left(E r+a E_{y}+a^{2} E b\right) / 3$

\section{NEGATIVE SEQUENCE VOLTAGE}

Negative sequence voltage is shown below in fig.3. Negative sequence voltage is calculated as follows:-

$\mathrm{E}_{\mathrm{r} 2}=\left(\mathrm{E}_{\mathrm{r}}+\mathrm{a}^{2} \mathrm{E}_{\mathrm{y}}+\mathrm{aE}_{\mathrm{b}}\right) / 3$ Where

$E_{r}$ is the voltage across $r$ phase. $E_{y}$ is the voltage across $y$ phase. $E_{b}$ is the voltage across $b$ phase. $a$ is the unit vector.

\section{Simulation Results}

Simulation results show the positive voltage compensation after occurrence of fault. Compensation of positive sequence voltage can be useful for improving system stability. Compensation is done by using available STATCOM current using PWM techniques. The graph below shows the positive sequence voltage compensation.
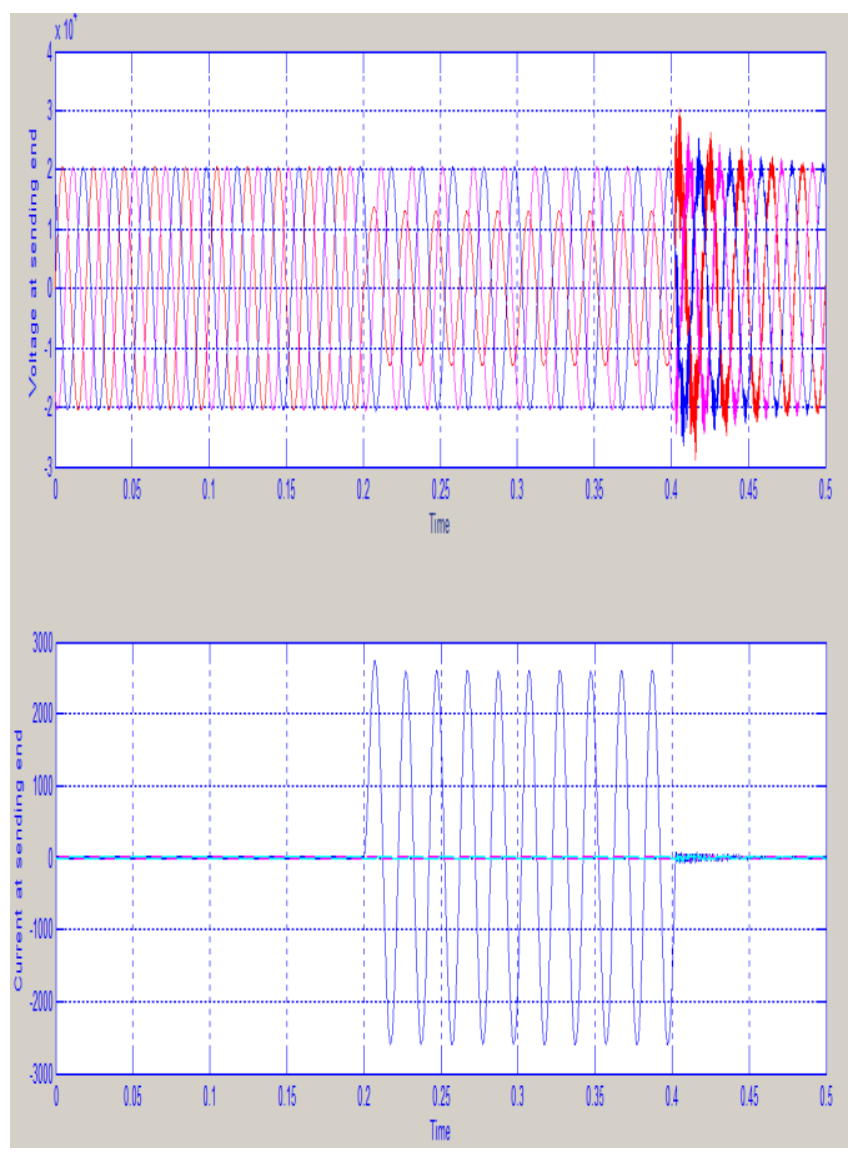

Fig.4 Voltage and current at sending end for single phase to ground fault without STATCOM 


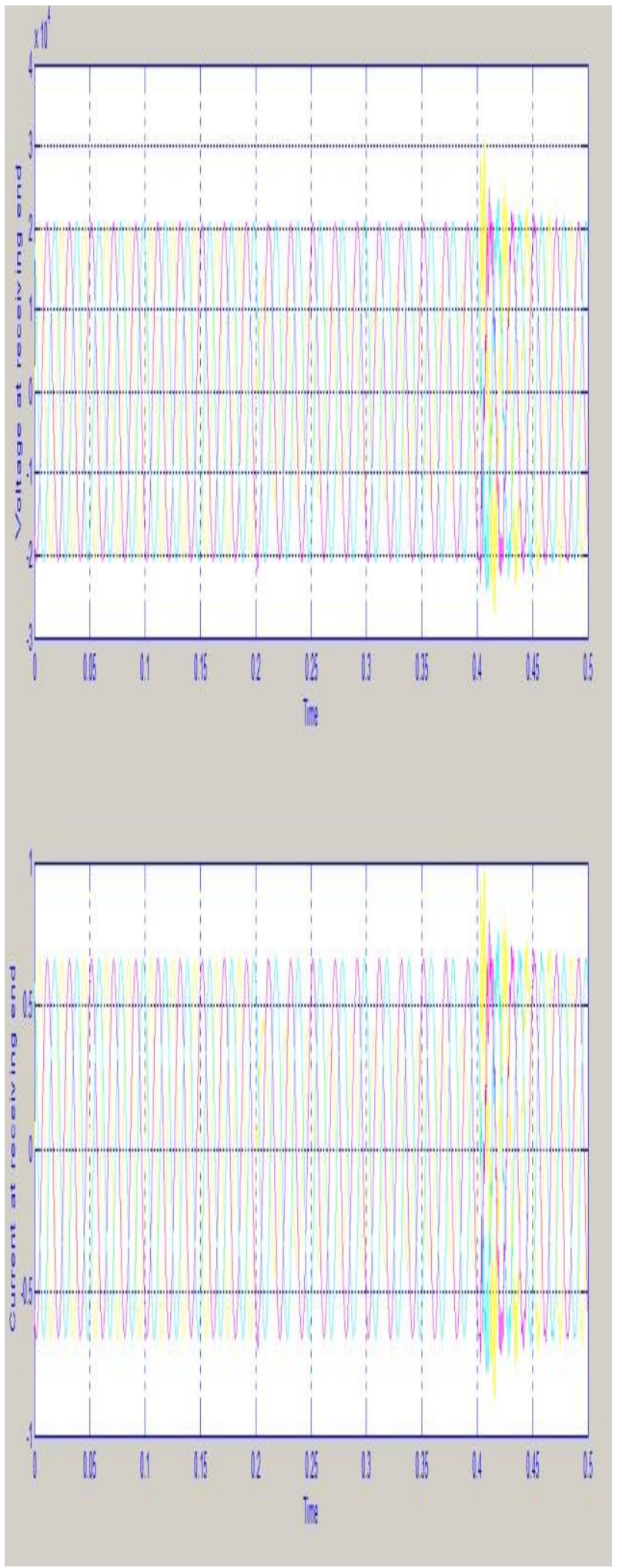

Fig.5 Voltage and current at receiving end for single phase to ground fault without STATCOM

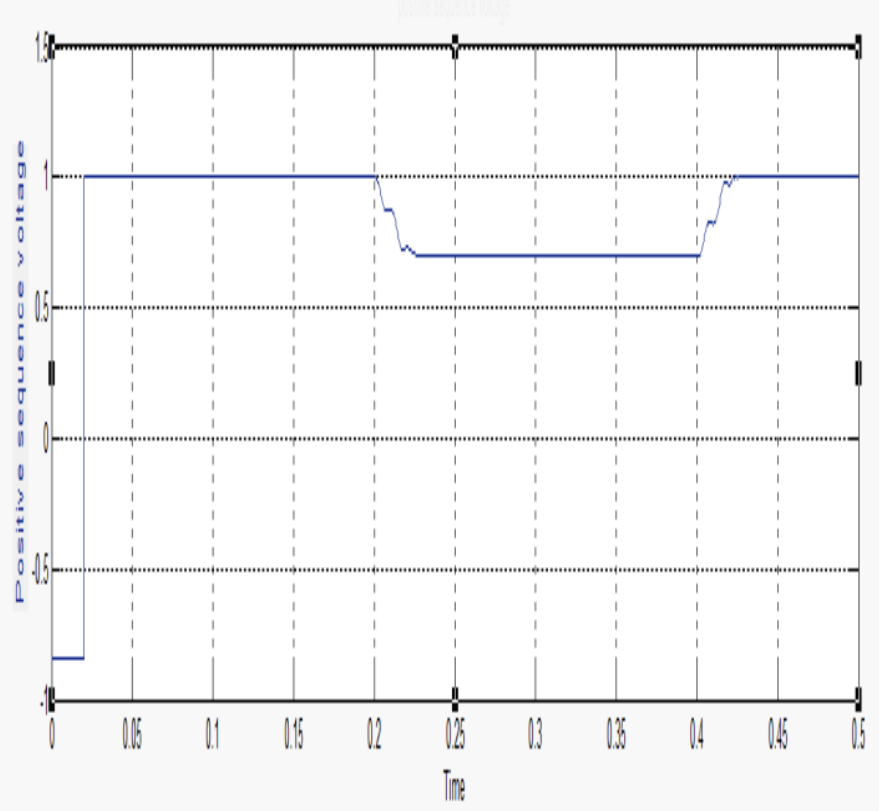

Fig.6 Positive sequence voltage without STATCOM for single phase fault

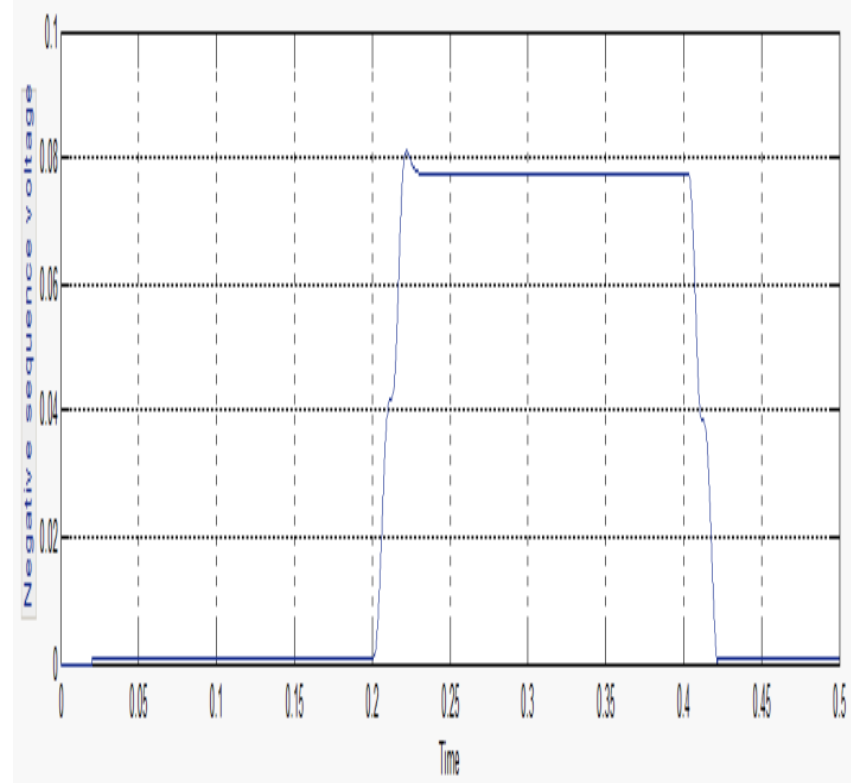

Fig.7 Negative sequence voltage without STATCOM for single phase fault 


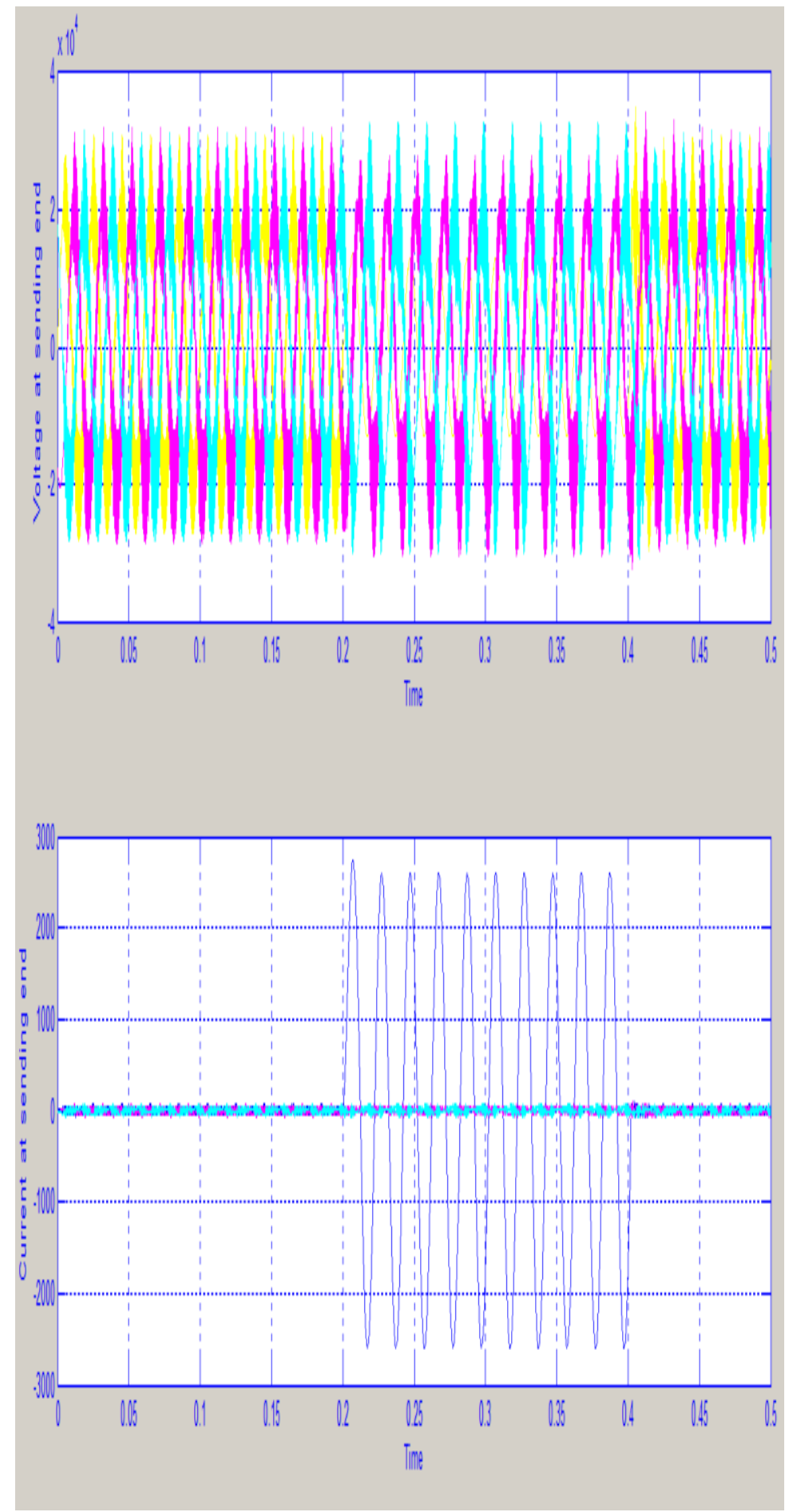

Fig.8Voltage and current waveforms at sending end with STATCOM for single phase fault

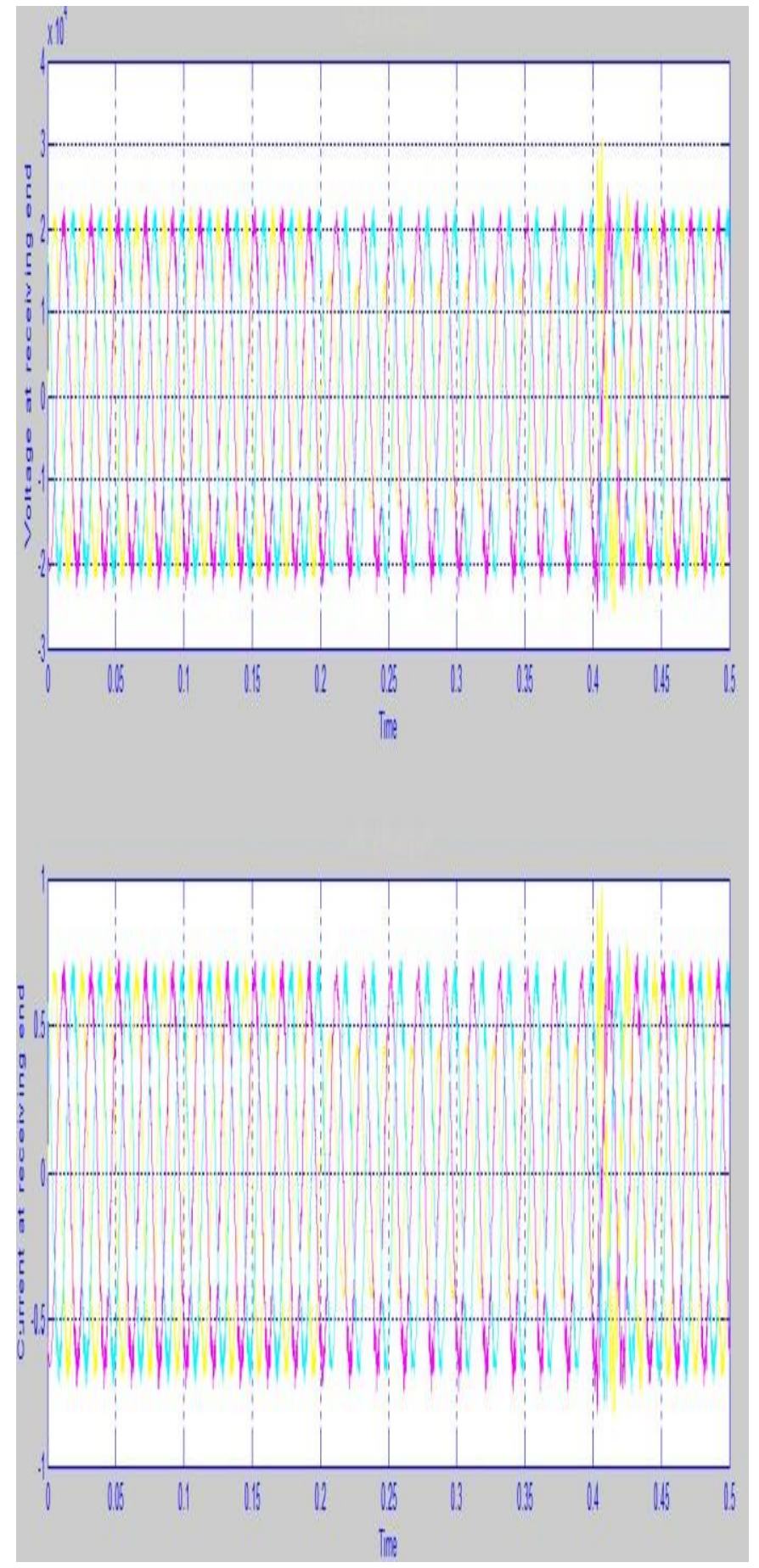

Fig.9 Voltage and current waveforms at receiving end with STATCOM for singe phase fault 


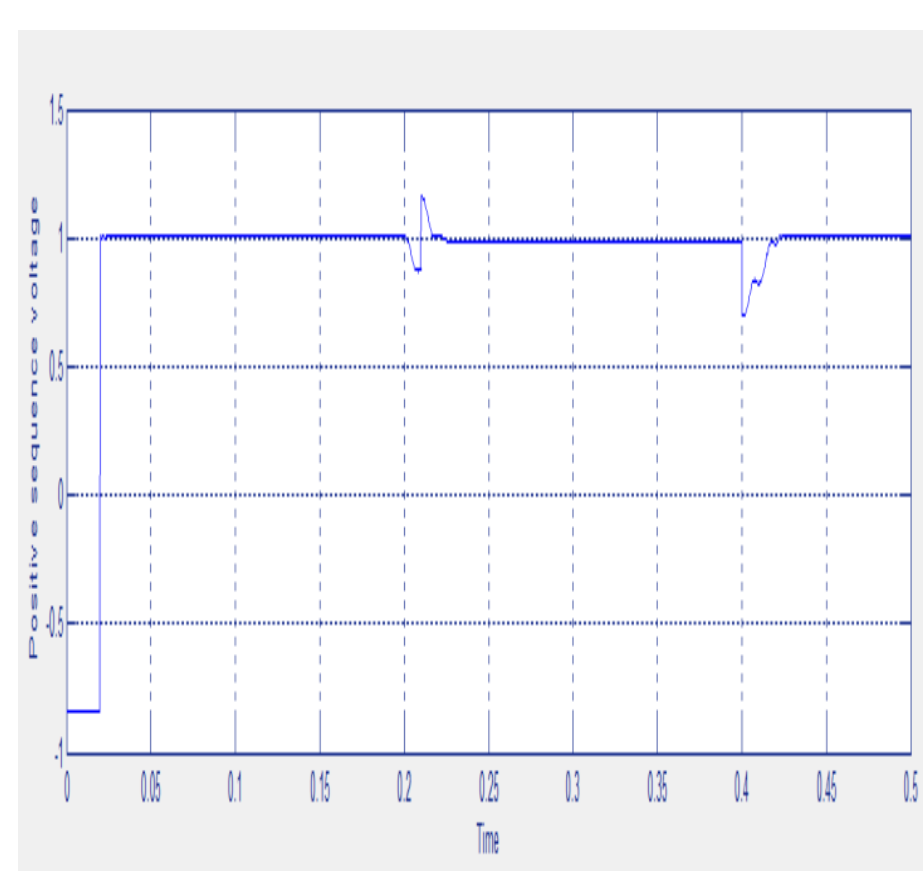

Fig.10 Positive sequence voltage with STATCOM for single phase fault

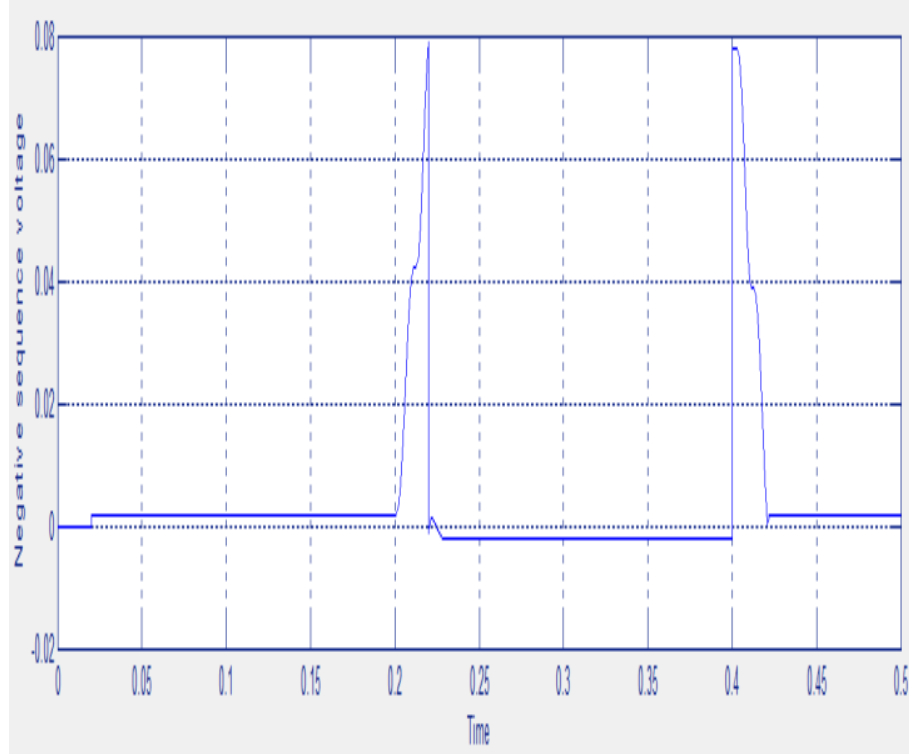

Fig.12 Voltage and current waveforms at sending end without STATCOM

15 for three phase to ground faults
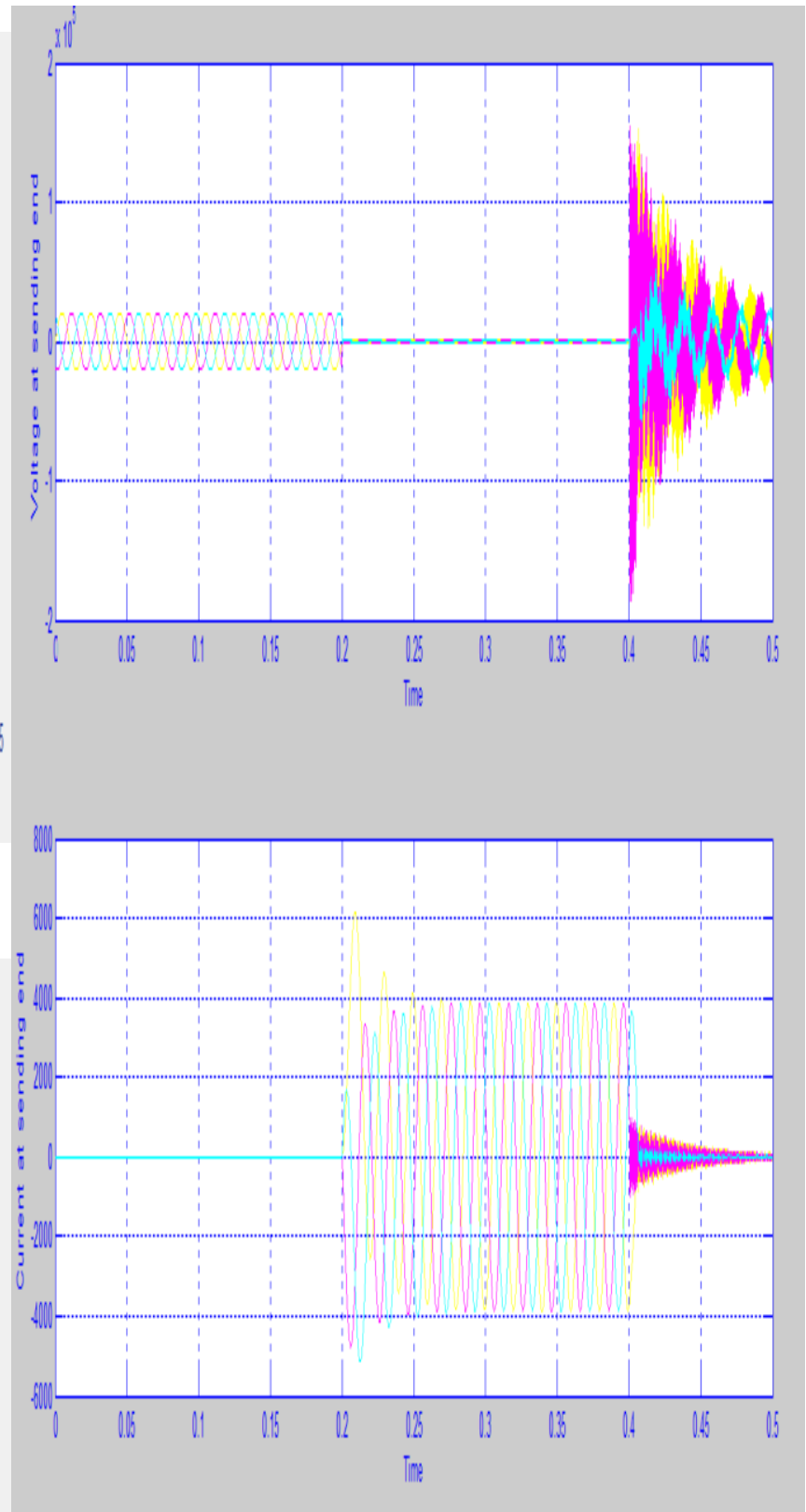

Fig.11 Negative sequence voltage with STATCOM for single phase fault 

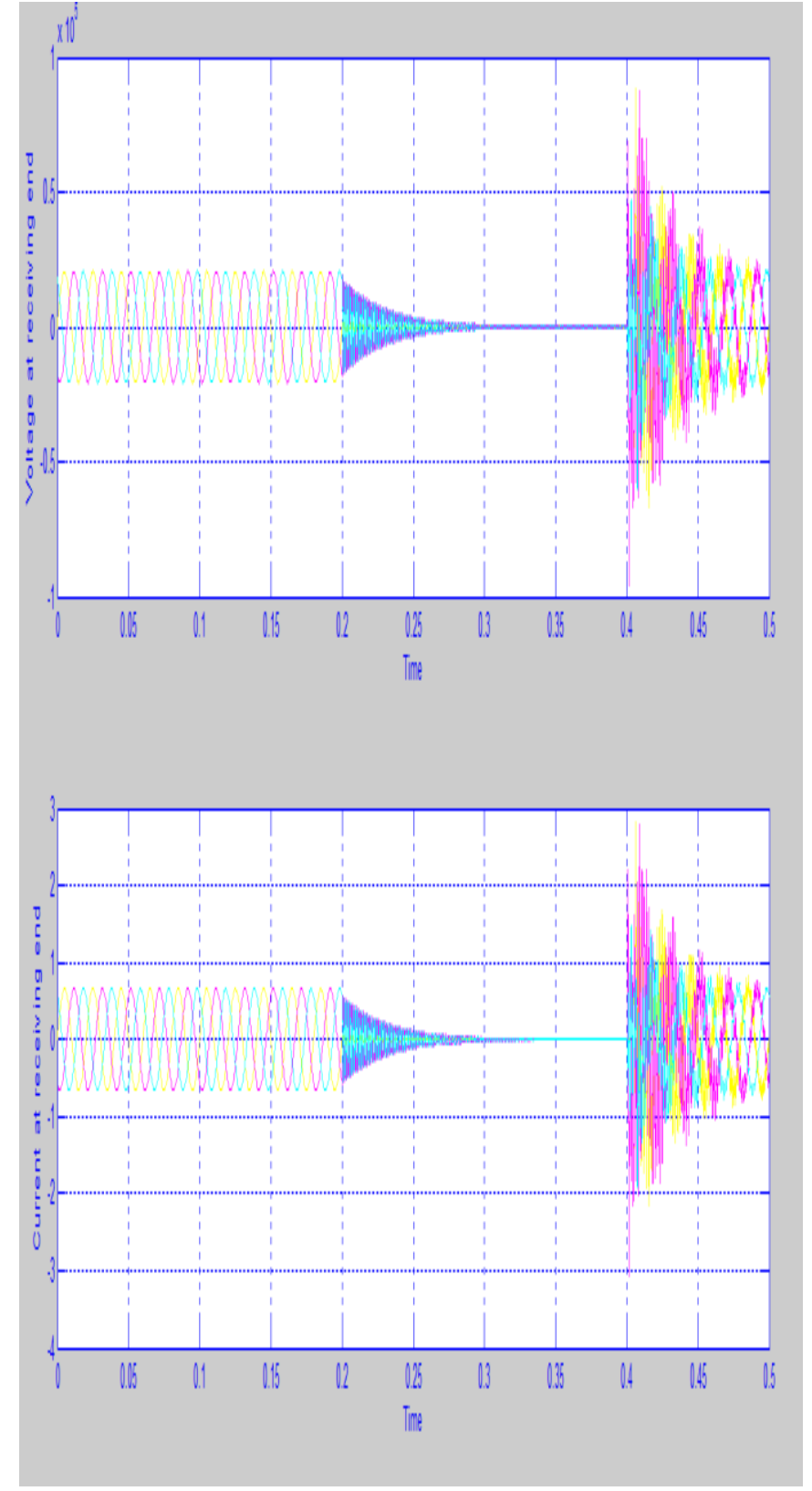

Fig.13 Voltage and current waveforms at receiving end without STATCOM for three phase to ground fault



Fig.14 Positive sequence voltage without STATCOM for three phase to ground fault

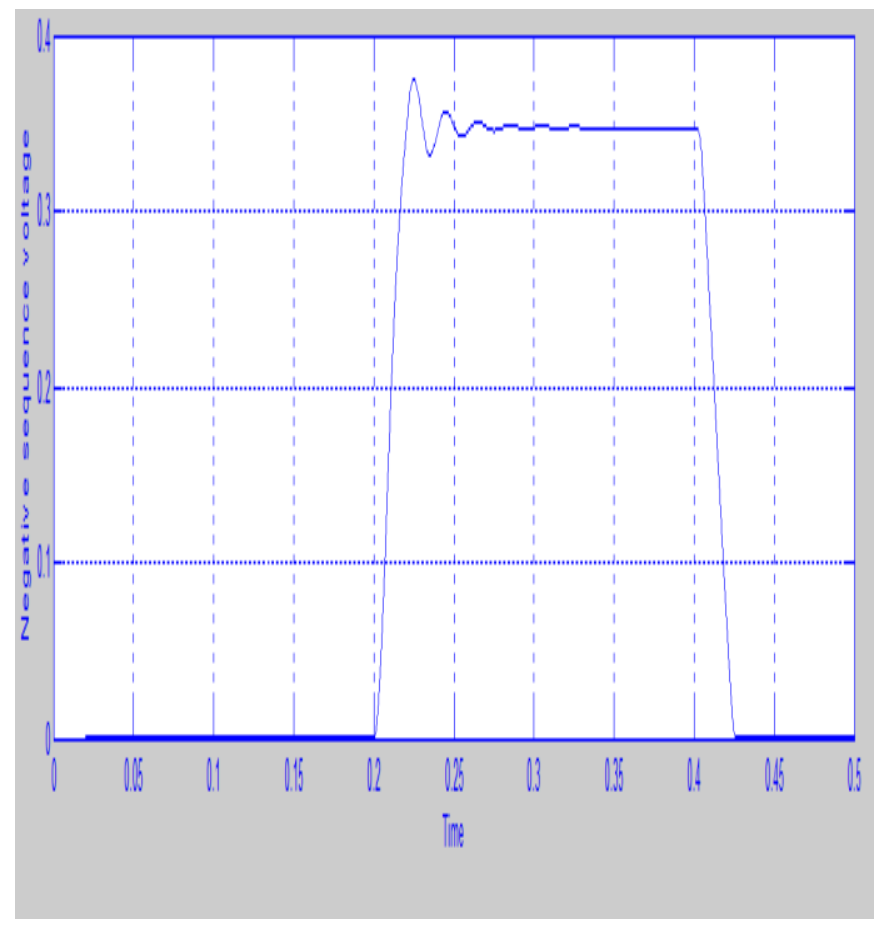

Fig. 15 Negative sequence voltage without STATCOM for three phase to ground fault 

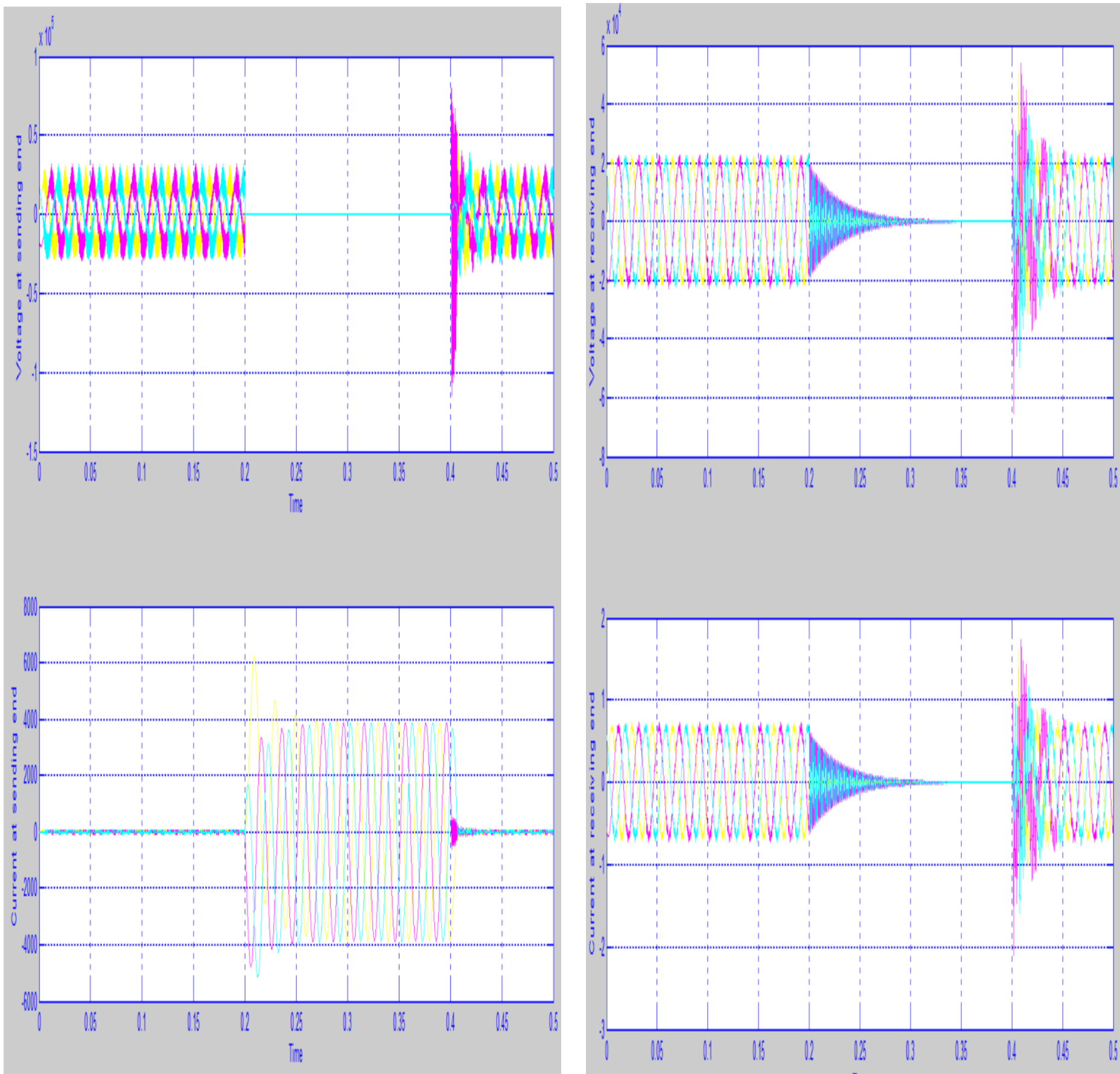

Fig. 16 Voltage and current waveforms at sending end with STATCOM for three phase to ground fault

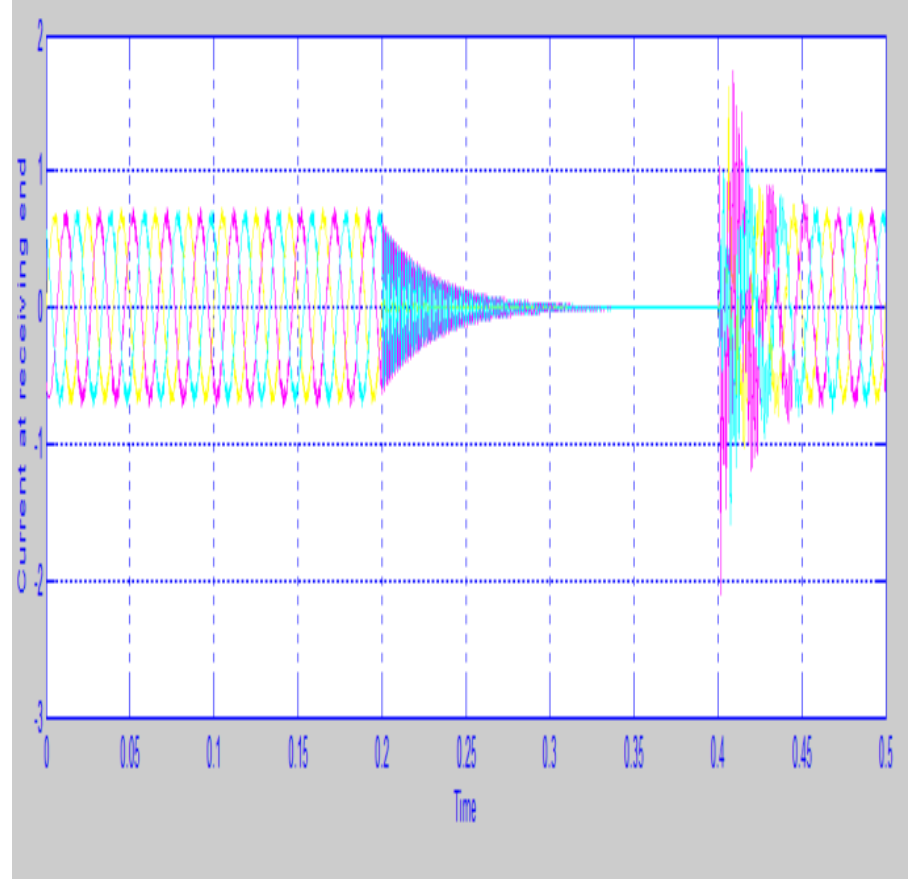

Fig.17 Voltage and current waveforms at receiving end with STATCOM for three phase to ground fault 


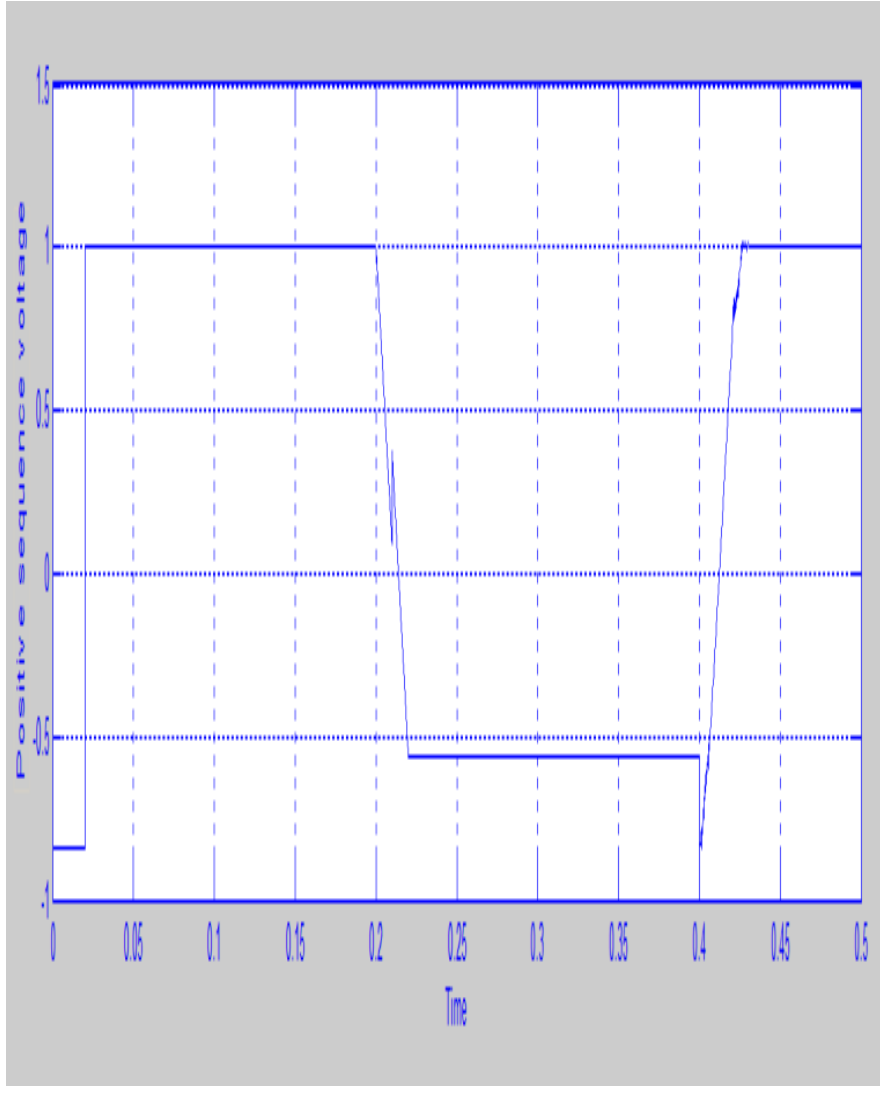

Fig.18 Positive sequence voltage with STATCOM for three phase to ground fault

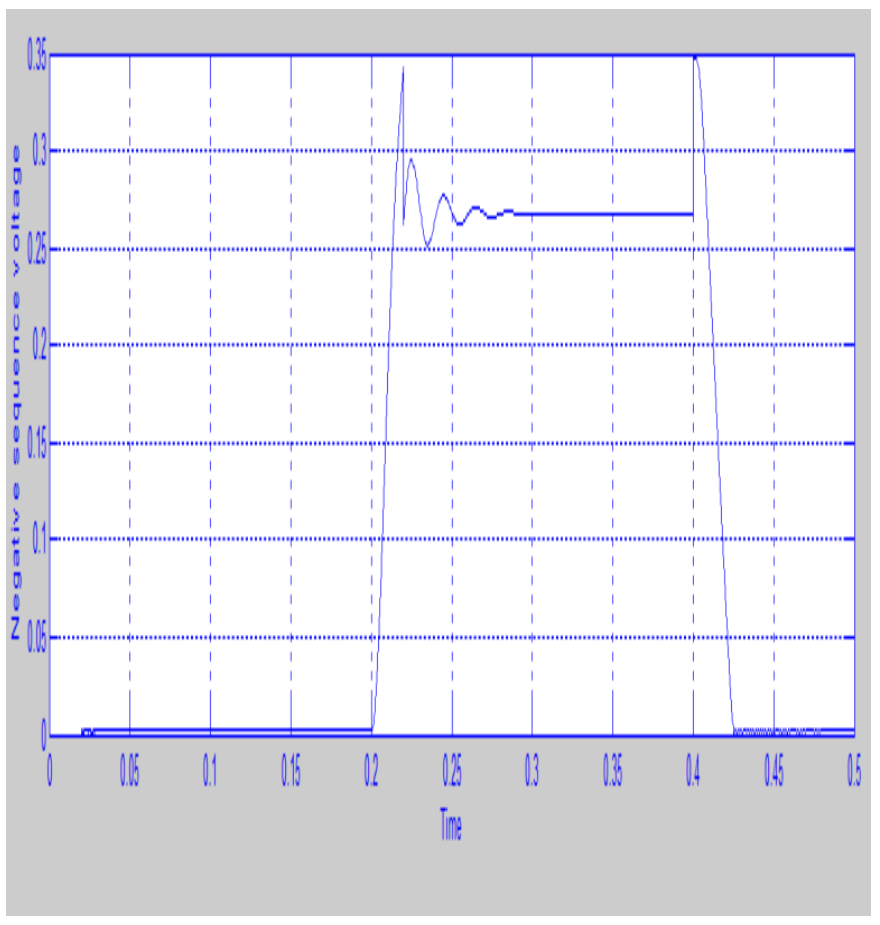

Fig.19 Negative sequence voltage with STATCOM for three phase to ground fault

\section{Conclusion}

In this project a wind turbine fed fixed speed induction generator is modeled under asymmetric grid fault $1 \mathrm{ph}-$ $50 \%$.To mitigate these faults a static compensator is injected into the wind turbine fed fixed speed induction generator. It also compensates the positive and negative sequence voltage and current. The respective waveforms are verified for without and with static compensator. Similarly the same procedure is evaluated $1 \mathrm{ph}-60 \%$ and $1 \mathrm{ph}-0 \%$ and the wind turbine characteristics have been worked out. Instead of fixed speed induction generator wind turbine fed doubly fed induction generator can be evaluated under asymmetric grid faults. Instead of STATCOM, DVR (dynamic voltage restorer), Unified power quality conditioner can used to attenuate the asymmetric faults in wind turbine fed FSIG and DFIG as both DVR and UPQC have the fault mitigation capability. The other combination that can be tried is permanent magnet synchronous generator with full back to back converter can be evaluated under asymmetric faults using different FACTS devices. Instead of PI controller, hysteresis controller can be employed and instantaneous theory; pq theory can be used in place of dq theory and evaluated.

\section{Acknowledgments}

I would like to show my sincere gratitude to Er. Ashish Jaiswal,Dr (Mrs) Palak Jaiswal, for their constant support and co-operation in this project. I would also like to thank my father Mr. Amit kumar Moitra and my mother Mrs. Smriti Moitra for their love and support and for always with me while completing this project. And at last I would like to thank my sister Miss Vaishali Moitra for being a mental support to me always.

\section{References}

[1]. Narain G. Hingorani and Laszlo Gyugyi,"Understanding FACTSConcepts and Technology of Flexible AC Transmission System,'New York,IEEE Press 2000

[2]. F. Van Hulle and N. Fichaux, "Powering Europe: Wind energy and the electricity grid," Eur. Wind Energy Assoc., Brussels, Belgium, Nov. 2010.K.

[3]. K.R.Padiyar,'Facts controllers in power transmission and distribution," New Age International (P) Ltd., 2007.

[4]. Christian Wessels, Nils Hoffmann, Marta Molinas and Friedrich Wilhelm Fuchs"StatCom Control at Wind Farms With FixedSpeed Induction Generators Under AsymmetricGrid Faults” IEEE Trans. Ind. Electron., VOL. 60, NO. 7, JULY 2013.

[5]. M.Ali and B.Wu, "Comparison of stabilization methods for fixed speed wind generator systems, " IEEE Trans.Power Del., vol. 25, no.1 pp,323- 331,Jan. 2010.

[6]. Diego Soto and Tim C. Green," A Comparison of High-Power Converter Topologiesm for the Implementation of FACTS Controllers," IEEE Transactions on industrial electronics, vol. 49,no.5,october 2002.

[7]. J.Suul, M. Molinas and T. Undeland,"STATCOM based indirect torque control of induction Machines during voltage recovery after grid faults," IEEE Trans. Power Electron.,vol.25,no.5,pp.12401250,May 2010.

[8]. Omar Noureldeen, "Low Voltage Ride through Strategies for SCIG Wind Turbines Interconnected Grid ," International Journal of Electrical \& Computer Sciences IJECS-IJENS vol: 11 No: 02 53, April 2011.

[9]. M. Noroozian,N Petersson, B. Thorvaldson, Bo A. 
Nilsson,C.W. Taylor, "Benefits of SVC and STATCOM for Electric Utility Application," IEEE Conference. Transmission and Distribution Conference and Exposition, 2003 IEEE PES ,vol.3,pp 1143 - 1150, Sept. 2003.

[10]. M. Sedighizadeh, A. Rezazadeh and M. Parayandeh, "COMPARISON OF SVC AND STATCOM IMPACTS ON WIND FARM STABILITY CONNECTED TO POWER SYSTEM," International Journal of Engineering and Applied Sciences(IJEAS)Vol.2, Issue 2,pp.13-22,2010.

[11]. Heng Nian, and Yipeng Song, "Direct Power Control of Doubly Fed Induction Generator Under Distorted Grid Voltage," IEEE TRANSACTIONS ON POWER ELECTRONICS, VOL. 29, NO. 2, FEBRUARY 2014

[12]. Balaji K, Madhusudanan G, "Modelling and Performance Analysis of a STATCOM Control for Induction Generator Based Windfarm under Unbalanced Loads,"International Journal of Engineering and Technical Research (IJETR) ISSN: 2321-0869, Volume-2, Issue-1, January 2014.

[13]. S. Engelhardt, J. Kretschmann, J. Fortmann, F. Shewarega, I. Erlich C. Feltes, "Negative Sequence Control of DFG based Wind Turbines," IEEE conf. Power and Energy Society General Meeting, pp. $1-8$, July 2011.

[14]. Yi Zhou, Paul Bauer, Jan A. Ferreira and Jan Pierik, "Operation of Grid-Connected DFIG Under Unbalanced Grid Voltage Condition,"IEEE TRANSACTIONS ON ENERGY CONVERSION, VOL.24, NO. 1, MARCH 2009.

[15]. Kanakarathinam.P, Manikandan.M, "Real and Reactive Power Compensation in Wind Farms by Static Synchronous Compensator," IJIRSET,International Conference on Engineering Technology and Science(ICETS'14), Volume 3,Special Issue 1, February 2014.

[16]. P. Rodriguez, G. Medeiros, A. Luna, M. Cavalcanti, and R. Teodorescu,"Safe current injection strategies for a STATCOM under asymmetrical grid faults," in Proc. IEEE ECCE, Sep. 2010, pp. 3929-3935.

[17]. Surekha Manoj,Puttaswamy Palahalli Srinivasaiah, "Improvement of Power Quality of Grid Integrated Wind Distributed Generation by STATCOM,"International Journal of Engineering and Advanced Technology(IJEAT), Volume-2,Issue-2,December 2012. 